\title{
Effect of the $\mathrm{Mg} / \mathrm{Al}$ ratio and of the rate of reinforcement on the synthesis of a nanocomposite Cellulose/Hydrotalcite
}

\author{
S. Mekdad ${ }^{a}$, M. Naciri Bennani ${ }^{a^{*}}$ M. Diouri ${ }^{b}$ \\ S. Mekdad \\ aLaboratory of chemistry-Biology Applied to the Environment, Research team " Applied Materials and \\ Catalyses " Chemistry Department, Faculty of Sciences, Moulay-Ismail University Meknes, Morocco

\section{soumiyamek@gmail.com \\ M. Naciri Bennani} \\ aLaboratory of Chemistry-Biology Applied to the Environment, Research team " Applied Materials and \\ Catalyses " Chemistry Department, Faculty of Sciences, Moulay-Ismail University, BP 11201 Zitoune Meknes, \\ Morocco

$$
\text { mbennanin@gmail.com }
$$

\section{Diouri} \\ 'Laboratory of plant Biotechnology and Molecular Biology, Research team "BVRV" Biology Department, \\ Moulay-Ismail University Meknes, Morocco
}

$$
\text { mo.diouri@gmail.com }
$$

${ }^{*}$ Corresponding author: mbennanin@gmail.com

\section{ABSTRACT}

The objective of this work is to synthesize a nonmaterial by introducing synthetic clay (hydrotalcite) as a nanofiller in a natural polymer matrix (cellulose) and to study the effect of $\mathrm{Mg} / \mathrm{Al}$ ratio and the rates of reinforcement.

Cellulose fibers were extracted from 'Yucca' tree's leaves by a chemical treatment and Hydrotalcite (MgAICO3) was synthesized by the method of co-precipitation at fixed $\mathrm{pH}$ with a ratio of $\mathrm{Mg} / \mathrm{Al}=2$ or 3 .

The composite materials were elaborated by microwave activation. The Hydrotalcites with an $\mathrm{Mg} / \mathrm{Al}$ ratio $=2$ or 3 were tested as well as various rates of reinforcement $(2,5$ or $10 \%$ Hydrotalcite) in order to optimize conditions of obtaining a nanomaterial.

The structures of obtained materials were characterized by IR spectroscopy, X-ray Diffraction and Transmission Electron Microscopy. The thermal stability was analyzed by TG-DTA analyses.

The characterizations carried out on these compounds revealed structural modifications in agreement with the formation of a nanomaterial (cellulose/Hydrotalcite) with the improved thermal properties.

\section{Indexing terms/Keywords}

Nanomaterial; biopolymers; cellulose; clays; hydrotalcite; layered double hydroxides "LDHs".

\section{Council for Innovative Research}

Peer Review Research Publishing System

Journal: Journal of Advances in Chemistry

Vol. 10, No. 4

editorjaconline@gmail.com

www.cirjac.com 


\section{INTRODUCTION}

During last years, the interest of research increased in the field of the polymer/clay nanocomposites. In most recent studies, the polymeric matrix is a synthetic polymer such as polyamides [1], polyimides [2], methacrylates [3, 4] or polystyrene [5]. Nevertheless, these synthetic materials cause a problem for the environment because of their lifespan higher than 400 years. Safeguarding of the environment passes by the conservation of fossil resources, reduction of greenhouse gas emissions and improvement of biodeterioration of the products. This context has a consequence on natural resources. Indeed, the biodegradable composites have attracted much attention because of their transparencies, their mechanical properties and their non toxicity [6].

Nanocomposites were elaborated with natural polymers such as cellulose acetate $[7,8]$ or with cellulose as reinforcing material but not as matrix [9, 10].

Several works concerned the synthesis of nanomaterials with polymer matrix and reinforced by natural or synthetic clay are developed. Delhom et al. [11] have studied the development of nanocomposite containing coton cellulosemontmorillonite clay for the use as a retarding flame material. Islam et al. [12] have synthesized cellulose-carbonated Hydroxyapatite nanocomposites for the retention of arsenic.

However, few authors were interested in the development of nanomaterials containing cellulose as matrix and of the layered double hydroxides 'LDHs' as reinforcements. For this reason we were interested in this work in the development of this type of compounds with two types of cellulose: a trade microcrystalline cellulose (MCC) and an extracted one. A synthesized $\mathrm{MgAlCO}_{3}$ Hydrotalcite with ratio of $\mathrm{Mg} / \mathrm{Al}=2$ or 3 was used.

Due to its low natural abundance, the Hydrotalcite, which belongs to the family of the layered double hydroxides "LDHs", can be obtained by synthesis in a broad field of composition. LDHs are composed of a stacking of layers of positively

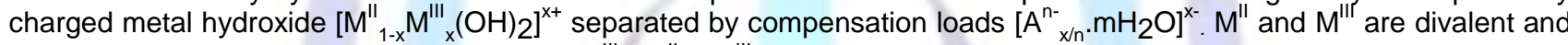
trivalent metal cations, $x$ is equal to the ratio $M^{\prime \prime \prime} /\left(M^{\prime \prime}+M^{\prime \prime \prime}\right)$ and $A^{n-}$ is an exchangeable anion of negative charge $n$.

The cellulose is the glucidic molecule, it is the most abundant organic substance on ground and is the main constituent of plants. This biopolymer draws an increasingly large attention due to its low cost, its relatively low density, its biodegrdability and availability, and its importance in the renewable chemical resources which replace materials containing oil [13].The separation of the biomass components (cellulose, hemicellulose and lignin) constitutes one of the principal obstacles to the effective use of the renewable resources [14,15]. Indeed, the extraction of cellulose requires mechanical and chemical treatments to eliminate lignin as well as the other components such as hemicellulose, organic resins, greases and waxes. Stages complementary to bleaching, drying and shaping come to supplement these treatments.

The species of yuccas of the family of the non fruit-bearing palm trees are in large plains, in mountains, coastal dunes, in the deserts, and even in the wet forests of Central America. They are used as decorative plants. Enormous quantities of residues of these species are burned and their combustion contributes to the pollution of the environment. However, these residues could find a way to more rational use, namely as a source of cellulose fibers. Therfore, we chose the foliage of this tree to extract cellulose.

Before starting the synthesis of required composite materials with as matrix of the extracted cellulose and as reinforcement Hydrotalcite clay, we carried out preliminary tests with microcrystalline cellulose (MCC) of trade. The latter was put beforehand in contact with a solution urea/ $\mathrm{NaOH}$ in selected proportions and during a given time. To the result, is added Hydrotalcite with $\mathrm{Mg} / \mathrm{Al}=2$ or 3 while varying, in each case, the load rate of the clay $(2,5$ and $10 \%$ of Hydrotalcite). An activation by microwave during 3 min with $350 \mathrm{~W}$ was used in the treatment.

The structures of the extracted biopolymer, of synthesized hydrotalcite and that of elaborate nanomaterial were revealed by the IR spectroscopy. Crystallinity and thermal stability were determined respectively using the X-ray diffraction and TGDTA analysis. The formation of the nonmaterial was examined by Transmission Electron Microscopy TEM.

\section{Material and methods}

\subsection{Material}

Natural cellulose was extracted from Yucca's leaves, harvested in Meknes (Morocco). Microcrystalline cellulose (MCC) was provided by Sigma-Aldrich. Salts of metals $\left(\mathrm{MgCl}_{2} \cdot 6 \mathrm{H}_{2} \mathrm{O}\right)$ and $\left(\mathrm{AlCl}_{3} \cdot 6 \mathrm{H}_{2} \mathrm{O}\right)$ with a content of $99 \%$, sodium hydroxide in the form of pearl with a purity of $98 \%$ and sodium carbonate $\left(\mathrm{Na}_{2} \mathrm{CO}_{3}\right)$ with a purity of $99.9 \%$ were provided by the LOBAChemie laboratory. 30\% hydrogen peroxide was provided by COGELAB. 99\% urea was provided by CHEMICAL. 92.14\% toluene was provided by BDH Limited Broom Road Poole England, and 99.9\% ethanol was provided by Riedel de Haën.

\subsection{Fiber treatment}

The collected samples were washed several times with water in order to eliminate any trace of mud, snipped in small pieces and dried in an oven for three days in order to standardize the residual water content. Then they were ground to pass through a 0.75 - or 1 - $\mathrm{mm}$ screen depending on the sample type. 


\subsection{Extraction of cellulose fibers}

$100 \mathrm{~g}$ of previously treated sample were placed in a soxhlet at backward flow provided with a filter cartridge, with an ethanol/toluene mixture $(=0.67)$ in order to eliminate pigments, lipids, waxes and all substances soluble in organic solvents [16]. After five passes at reflux, the recovered sample was placed in a solution of $18 \% \mathrm{NaOH}+30 \% \mathrm{H}_{2} \mathrm{O}_{2}$. This mixture, of green color, is agitated and heated at $40^{\circ} \mathrm{C}$ for one day. After return to ambient temperature, it was filtered and rinsed several times with distilled water until neutralization of the medium $(\mathrm{pH}=7)$. The paste obtained then was underwent a bleaching treatment with a $12 \%$ solution of sodium hypochlorite. After washing with distilled water and drying at $60^{\circ} \mathrm{C}$ overnight, resulting fibers were characterized by X-ray diffraction and IR spectroscopy.

\subsection{Synthesis of hydrotalcite $\mathrm{MgAlCO}_{3}(\mathrm{Mg} / \mathrm{Al}=2$ and 3)}

Hydrotalcite $\mathrm{MgAlCO}_{3}$ was prepared by the coprecipitation method at constant $\mathrm{pH}$, which consists in preparing two solutions of equal volume of water. A first aqueous solution of aluminum and magnesium chloride salt, defined by a molar ratio $\mathrm{Mg} / \mathrm{Al}=2$ and 3 , was obtained by dissociating 0.2 or 0.3 mole of $\mathrm{MgCl}_{2} .6 \mathrm{H}_{2} \mathrm{O}$ and 0.1 mole of $\mathrm{AlCl}_{3} .6 \mathrm{H}_{2} \mathrm{O}$ in $300 \mathrm{ml}$ of distilled water. A second solution was prepared by dissolving $2.12 \mathrm{~g}$ of sodium carbonate $\left(\mathrm{Na}_{2} \mathrm{CO}_{3}\right)$ and $32 \mathrm{~g}$ of sodium hydroxide $(\mathrm{NaOH})$ in $300 \mathrm{ml}$ of distilled water.These two solutions were mixed drop wise while maintaining the $\mathrm{pH}$ to a basic value (between 10 and 11) and under magnetic stirring. The temperature was kept during mixing between $60^{\circ} \mathrm{C}$ and $70^{\circ} \mathrm{C}$. The mixture was then refluxed at $65^{\circ} \mathrm{C}$ for 17 hours to allow crystal growth. After return to room temperature, the precipitate was filtered and the solid obtained was washed several times with warm distilled water until complete elimination of excess chlorides (test with $\mathrm{AgNO}_{3}$ ) and then dried in an oven at $70^{\circ} \mathrm{C}$ during $15 \mathrm{~h}$.

\subsection{Synthesis of the nanocomposite}

The preparation of nanocomposites MCC-HT3 and MCC-HT2 was carried out by dispersing the argillaceous load (HT) in the polymer (MCC). $8.14 \mathrm{~g}$ of microcrystalline cellulose (MCC) were added to a solution $\mathrm{NaOH} / \mathrm{urea} / \mathrm{H}_{2} \mathrm{O}$ with a weight ratio of $28 / 48 / 320$. The whole was then stirred for 12 hours and cooled to $5^{\circ} \mathrm{C}$ in a refrigerator.

A desired quantity of hydrotalcite $\mathrm{HT}(\mathrm{Mg} / \mathrm{Al}=3$ or 2$)$ synthesized was dispersed in the cellulose solution prepared above. The reaction mixture was left under agitation during one night.This new solution, of a creamy texture, was treated in a domestic furnace with microwave [15] during $3 \mathrm{~min}$ at 350 Watt (optimal conditions obtained during the previous tests) and then centrifuged at $3000 \mathrm{rpm}$ during $12 \mathrm{~min}$. The Hydro gel obtained was washed with a mixture of distilled water/ethanol $(50 \mathrm{v} / 50 \mathrm{v})$ and dried in an oven at $50^{\circ} \mathrm{C}$ for 7 hours.

The percentages of cellulose/Hydrotalcite $(\mathrm{Mg} / \mathrm{Al}=\mathrm{x})$ for the nanomaterial prepared and studied are 98/2, 95/5 and 90/10. These resulted solids were noted: HTx, MCC-HTx.2\%, MCC-HTx.5\%, MCC-HTx.10\% (with x=2 or 3).

\subsection{Analysis}

The extracted polymer, the hydrotalcites synthetized, the microcrystalline cellulose and the elaborated composite materials were characterized by various physicochemical techniques (XRD, IR, TG-DTA and TEM).

\subsubsection{X-rays Diffraction}

Powder XRD of the material was obtained by using Philips PW 1130/90 X-Ray diffractometer, available in our laboratory, with $\mathrm{Cu} \mathrm{Ka}$ radiation $(40 \mathrm{kV}$ and $20 \mathrm{~mA})$ at a scan rate of $1 \% / \mathrm{min}$. Then, it was analyzed using a standard software provided with the instrument.

The index of crystallinity of cellulose was calculated starting from XRD spectrum according to the following equation [17].

$$
I c r=\frac{I(002)-I(\mathrm{am})}{I(002)}
$$

With $\mathrm{I}(002)$ and $\mathrm{I}(\mathrm{am})$ represent respectively the intensities of the diffraction peaks $(002)$ at $2 \theta=22^{\circ}$ and of the diffraction peak corresponding to amorphous cellulose at $2 \theta=16^{\circ}$.

\subsubsection{Infra-red Spectroscopy}

The FTIR of the sample was obtained using JASCO 4100 FTIR spectrophotometer (provided with a detector TGS and a source of ceramics, separated by optical system using a Michelson interferometer). The FTIR spectrum of the sample was obtained by $\mathrm{KBr}$ pellet method. The ratio of the sample to $\mathrm{KBr}$ was 1:50 and the pellet was prepared at a pressure of 5 Ton. The corresponding spectra were recorded between 400 and $4000 \mathrm{~cm}^{-1}$ (Resolution: $4 \mathrm{~cm}^{-1}$ initial Intensity of beam: 22000).

\subsubsection{TG-DTA analyses}

Thermogravimetric (TG-DTA) analysis was carried out using Shimadzu TA-60. 30mg of the sample was used. TG and DTA curve was obtained from $20^{\circ} \mathrm{C}$ to $600^{\circ} \mathrm{C}$ at a heating rate of $10^{\circ} \mathrm{C} / \mathrm{min}$. 


\subsubsection{TEM analyses}

Transmission Electron Microscopy imaging of the sample was obtained by the microscope type Tecnai G2 from FEI Company.It is available at National Center for Scientific and Technical Research (CNRST) in Rabat, Morocco. The sample was coated with platinum for $30 \mathrm{~s}$ at a current of $50 \mathrm{~mA}$ and the SEM micrograph was obtained.

\section{Results and discussion}

\subsection{Study by XRD}

Fig. 1(a) shows the X-ray powder diffraction patterns of synthesized hydrotalcites.
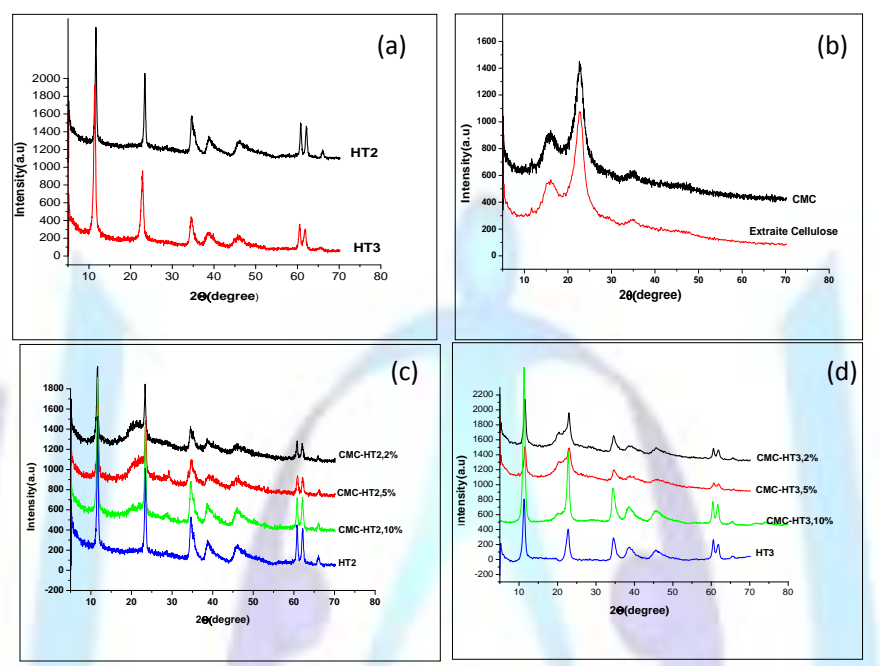

Figure 1: XRD plot of various samples a) HT3 and HT2; b) Extracted cellulose and MCC; c) Nanocomposites MCC-HT2.y; d) Nanocomposites MCC-HT3.y ( $y=2,5$ and 10\%).

It is noted that the patterns of HT2 and HT3 show the presence of the whole diffraction peaks (00I) generally met in the compounds with lamellar structure [18].These peaks are fine and are well solved, which indicates that the compounds obtained present pure and well-crystallized Hydrotalcite phase. The average size of the particles is calculated using the law of Debye-Scherrer :

$$
D=\frac{1 k \cdot \lambda}{\sqrt{\left(L^{2}-1^{2}\right) \cdot \cos \theta}}
$$

With $\lambda$ corresponds to the peak diffraction $\mathrm{Ka}$ of copper $(\lambda=1.5418 \AA), \theta=$ angle of diffraction peak $(003), K=$ factor of correction ( $\mathrm{k}=0.89$ ), $\mathrm{L}=$ width with middle height of peak diffraction (003) (in ${ }^{\circ}$ ) and $\mathrm{I}=0,133^{\circ}$ (mica blade).

The values obtained are gathered in Table 1:

Table 1: Average sizes of the particles relating to the diffraction peak (003) of the samples HT2 and HT3.

\begin{tabular}{|l|l|l|l|}
\hline Compound & $L\left(^{\circ}\right)$ & $\theta\left(^{\circ}\right)$ & $D(\mathrm{~nm})$ \\
\hline HT2 & 0.447 & 5.80 & 18.71 \\
\hline HT3 & 0.700 & 5.66 & 19.70 \\
\hline
\end{tabular}

According to these values, we can note that for materials HT2 and HT3, the Hydrotalcite particles are of nanometric size.

The X-rays spectrum of extracted cellulose is given in the figure1(b). The spectrum presents three diffraction peaks located at $2 \theta=16^{\circ}, 22^{\circ}$ and $34^{\circ}$.

The diffraction peaks observed around $2 \theta$ of $16^{\circ}$ correspond to the diffraction of the plan (110) and represent amorphous cellulose. The diffraction peaks at $2 \theta$ of $22^{\circ}$ and $34^{\circ}$ correspond respectively to diffractions of the plans (002) and (004) and are attributed to the crystalline shape of the cellulose [19]. However, we note the presence of a peak of low intensity at $2 \theta=11.36^{\circ}$ due to traces of Hémicellulose or lignin. 
The index of crystallinity of cellulose extracted, calculated starting from relation $\mathrm{I}_{\mathrm{cr}}$ is equal to 0.76 . The comparison with the index of the MCC (0.81) indicates that the extracted cellulose has a good crystallinity and a good purity.

The X-rays spectrum of developed composites is presented on Figure 1 ( $c$ and d). They present all, in addition to the characteristic peaks of Hydrotalcite phase, an extra wide stripe, overlapped with the stripe (006) of Hydrotalcite, located towards $2 \theta=20^{\circ}$ and which corresponds to the most intense peak of microcrystalline cellulose (Fig. $1 \mathrm{~b}$ ).

In all cases, we observed also the disappearance of the peak towards $2 \theta=16^{\circ}$ (Fig. $1 \mathrm{~b}$ ) corresponding to the amorphous shape of cellulose, which lets think that for the composites prepared, the cellulose is in an ordered form.

However in the case of the samples MCC-HT2.5\% and MCC-HT2.10\%, we observed a stripe of low intensity towards $2 \theta$ of $29^{\circ}$ and which can be due to the formation of another phase when the load rate increases for the nanocomposite of Hydrotalcite with the ratio $\mathrm{Mg} / \mathrm{Al}=2$. This peak does not appear for the composites with HT3 (MCC-HT3.5\% and MCCHT3.10\%). This can be related to the load of the layer of the Hydrotalcite which is weaker in the case of HT3 due to the influence of the ratio $\mathrm{Mg} / \mathrm{Al}$ on the synthesis of composite materials.

\subsection{Study by IR spectroscopy}

The spectra of HT2 and HT3 (Fig.2a) present the structural features of compounds of MgAICO3 hydrotalcite type [18].The principal bands and their attributions are presented in Table 2.
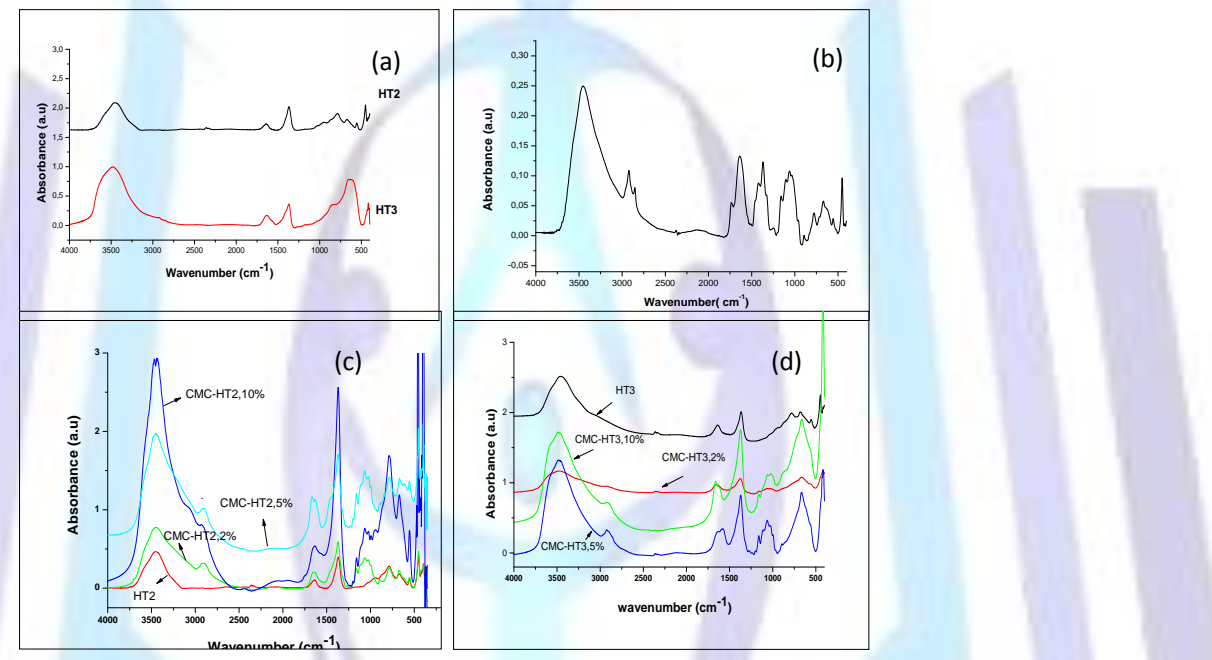

Figure 2: Infra-red spectra of various samples a) HT2 and HT3, b) extracted cellulose, c) MCC-HT2.y and d) MCCHT3.y ( $y=2,5$ and $10 \%)$.

Table 2: Main vibrations bands of HT2 and HT3 and their attributions.

\begin{tabular}{|l|l|l|l|l|l|l|}
\hline & & & & \multicolumn{3}{|c|}{$1100-400 \mathrm{~cm}^{-1}$} \\
\hline $\mathrm{v}\left(\mathrm{cm}^{-1}\right): \mathrm{HT2}$ & 3457 & 637 & $1370 ; 950$ & $783 ; 663$ & 555 & 445 \\
\hline $\mathrm{v}\left(\mathrm{cm}^{-1}\right): \mathrm{HT} 3$ & 3452 & 682 & $1360 ; 948$ & $783 ; 682$ & 555 & 454 \\
\hline Attributions & $\mathrm{v}_{\mathrm{as}(\mathrm{OH})}$ & $\delta_{(\mathrm{H} 2 \mathrm{O})}$ & $\left.\mathrm{v}_{\mathrm{as}} ; \mathrm{v}_{\mathrm{s}(\mathrm{CO})}\right)$ & $\delta_{(\mathrm{OH})}$ & $\mathrm{v}_{(\mathrm{M}-\mathrm{O})}$ & $\mathrm{v}_{\left(\mathrm{M}-\mathrm{O}-\mathrm{M}^{*}\right)}$ \\
\hline
\end{tabular}

${ }^{*} \mathbf{M}=$ Metal.

The IR spectrum of extracted cellulose is represented in figure $2 \mathrm{~b}$.It shows the characteristic bands of cellulose. The bands located towards 3400 and $2900 \mathrm{~cm}^{-1}$ correspond respectively to the stretching of $\mathrm{O}-\mathrm{H}$ and $\mathrm{C}-\mathrm{H}$ group of the cellulose [19]. A band at $1636 \mathrm{~cm}^{-1}$ is attributed to adsorbed water. The $1370 \mathrm{~cm}^{-1}$ band reflects the asymmetrical deformation of $\mathrm{C}-\mathrm{H}$ of cellulose [20]. On the other hand, we note the existence of two additional bands of low intensity towards 2860 and 1720 $\mathrm{cm}^{-1}$ respectively assigned to lignin and hemicellulose [21] (Fig.2b) which confirms the existence of traces from these two compounds in extracted cellulose, as has been observed by XRD (Fig.1b).

The IR spectra of the composites with various \% of clay present all the characteristic bands of Hydrotalcite and cellulose (Fig.2c and 2d). We note, for composite materials, the presence of the band around $3400 \mathrm{~cm}^{-1}$ due to the vibrations of stretching of $\mathrm{OH}$ group.The intensity of this band increases with the rate of reinforcement, compared with HT2 and HT3 alone, because it covers both band $\mathrm{O}-\mathrm{H}$ of the hydroxyl groups of the Hydrotalcite layers and band $\mathrm{O}-\mathrm{H}$ of vibration of elongation of the alcohol functions of the cellulose [22].The absorption bands located around $2924 \mathrm{~cm}^{-1}$ and $1060 \mathrm{~cm}^{-1}$ observed on the spectra of MCC-HTx.2\%, MCC-HTx.5\%, MCC-HTx.10\% ( $\mathrm{x=2}$ or 3), are respectively associated with 
stretching vibration of cellulose $\mathrm{C}-\mathrm{H}[23,24]$ and the anti-symmetric vibrations of elongations $\mathrm{C}-\mathrm{O}-\mathrm{C}$ of glycosidic linkage [25].The presence of the $\mathrm{CH}$ group is supported by the band of vibration around $1460 \mathrm{~cm}^{-1}$ as it was observed by UlIslama et al. [26] during the preparation of the bacterial cellulose-montmorillonite composite for medical applications.

All these observations support the hypothesis of the dispersion of the Hydrotalcite nanoparticles in the cellulose matix and thus confirm the formation of the nanocomposite by the presence of mixed phase HT-MCC in agreement with the results of the analysis by X-rays diffraction.

We followed the evolution of $\mathrm{C}-\mathrm{H}$ band characteristics of the presence of cellulose phase in composite materials by examining the intensity ratio of the stretching band $\mathrm{C}-\mathrm{H}$ of cellulose skeleton on the vibration band of hydroxyl group

$\mathrm{Iv}_{\mathrm{C}-\mathrm{H}} / \mathrm{Iv} \mathrm{O}-\mathrm{H}$ (Fig.3).

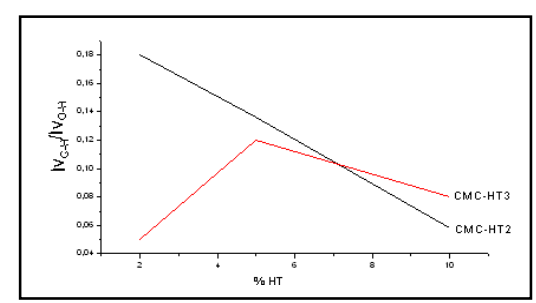

Figure 3: Evolution of $\mathrm{Iv}_{\mathrm{C}-\mathrm{H}} / \mathrm{l} \mathrm{v}_{\mathrm{O}-\mathrm{H}}$ ratio according to the rate of reinforcement (2, 5 and $\left.10 \%\right)$ for MCC-HT2 and MCC-HT3.

It is noted that the ratio $\mathrm{IV}_{\mathrm{C}-\mathrm{H}} / \mathrm{Iv}_{\mathrm{O}-\mathrm{H}}$ is maximal for the composite MCC-HT2.2\% and passes by an optimum of $5 \%$ in the case of MCC-HT3. What lets consider, that for $2 \%$ (case of HT2) and $5 \%$ (case of HT3) of load there would be a strong interaction between the Hydrotalcite particles and the cellulose matrix and thus a better association of clay and the polymer, respectively for the Hydrotalcite of ratio $\mathrm{Mg} / \mathrm{Al}=2$ and 3. This result can be compared with the work of Bao Yongzhong et al. [27].The authors observed that the P.V.C-Hydrotalcite nanocomposites with $2.5 \%$ and $5.3 \%$ load show the improved properties in term of thermal stability and flame emission. In addition, it is observed that this ratio $\mathrm{IV}_{\mathrm{C}-\mathrm{H}} / \mathrm{Iv}_{\mathrm{O}-\mathrm{H}}$, except for HT3.10\%, is more significant for the composites prepared with HT2. This result describes the influence of the $\mathrm{Mg} / \mathrm{Al}$ ratio and thus the load of hydrotalcite layers. When the quantity of aluminum decreases, the charge of layers of hydrotalcite decreases. Therefore less of aluminum hinders the dispersion of particles of Hydrotalcite within polymer matrix.

\subsection{Thermal study}

In parallel of the analyses by XRD and IR, it was interesting to investigate the thermal stability of MCC, HT2, HT3, MCC$\mathrm{HT} 2.2 \%$, MCC-HT2.5\% and MCC-HT3.5\% materials, using thermogravimetric analysis (TGA) and differential thermal analysis (DTA). We chose these samples to check the influence of \% of reinforcement and of the $\mathrm{Mg} / \mathrm{Al}$ ratio of the solid. The thermogravimetric analysis is given respectively in figure $4 \mathrm{a}$ and $\mathrm{b}$.
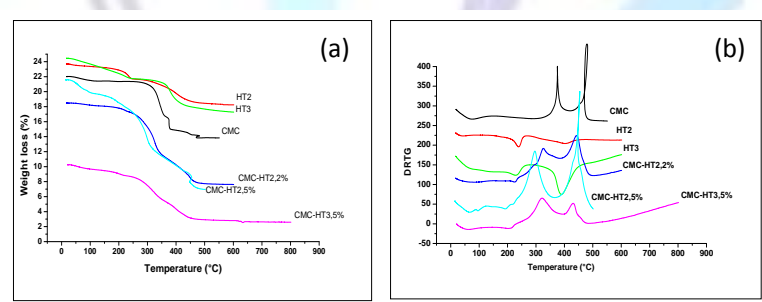

Figure 4: a) TG and b) DTG curves of various samples: MCC, HT2, HT3, MCC-HT2.2\%, MCC-HT2.5\% and MCCHT3.5\%.

The heat treatment of synthesized Hydrotalcites HT2 and HT3 leads to a weight loss in three stages. The first loss corresponds to desorption of adsorbed water (peak of low intensity towards $43.5^{\circ} \mathrm{C}$ for $\mathrm{HT} 2$ and $46.0^{\circ} \mathrm{C}$ for $\mathrm{HT} 3$ ). The second loss (peak towards $238.4^{\circ} \mathrm{C}$ with $\Delta \mathrm{m}=11.8 \%$ for $\mathrm{HT} 2$ and $228.3^{\circ} \mathrm{C}$ with $\Delta \mathrm{m}=5.3 \%$ for $\mathrm{HT} 3$ ) is attributed to the elimination of water molecules located in the interfoliaceous field. In the third stage, there occurs the departure of $\mathrm{CO}_{2}$ by decarboxylation of compensation anions and the water molecules by dehydroxylation of the layers $(\Delta \mathrm{m}=23.3 \%$ for $\mathrm{HT} 2$ and $\Delta \mathrm{m}=24.9 \%$ for $\mathrm{HT} 3$ ). It gives the temperature peak located towards $401.9^{\circ} \mathrm{C}$ for $\mathrm{HT} 2$ and $389.7^{\circ} \mathrm{C}$ for $\mathrm{HT} 3$ (Table 3 ). The total weight loss at $600^{\circ} \mathrm{C}$ is $37.5 \%$ for $\mathrm{HT} 2$ and $40.8 \%$ in the case of HT3 (Table 4).

The thermogravimetric analysis of the microcrystalline cellulose MCC, shows an endothermic peak located towards $75.8^{\circ} \mathrm{C}$ due to the removal of physisorbed water $(\Delta \mathrm{m}=5.6 \%)$ and two other exothermic peaks of crystallization (Fig, $\left.4 \mathrm{~b}\right)$. These peaks temperatures in DT curve are $\mathrm{T}^{\prime}{ }_{1}=375.4^{\circ} \mathrm{C}$ and $\mathrm{T}^{\prime} 2=479.1^{\circ} \mathrm{C}$ (Table 3 ), and their weight losses are respectively about $64.4 \%$ and $9.0 \%$ which correspond to the decomposition of cellulose [28].

The thermogravimetric analysis of nanocomposites presents the typical peaks of Hydrotalcite and cellulose, with modified temperatures and weight loss (Table 3 and 4), which confirms the formation of mixed phase as it was observed by XRD and IR. 
Table 3: Values of the temperature maxima taken from the thermogravimetric analysis of HT2, HT3, MCC, MCCHT2.5\%, MCC-HT3.5\% and MCC-HT2.2\%.

\begin{tabular}{|l|l|l|l|l|l|l|}
\hline T $\left({ }^{\circ} \mathrm{C}\right)$ & T1 & T2 & T3 & T4 & T'1 & T'2 \\
\hline MCC & 75.8 & & & & 375.4 & 479.1 \\
\hline HT2 & 43.5 & & 238.4 & 401.9 & & \\
\hline HT3 & 46.0 & & 228.3 & 389.7 & & \\
\hline MCC-HT3.5\% & 62.0 & & 201.5 & - & 321.5 & 430.9 \\
\hline MCC-HT2.5\% & 66.7 & 95,40 & 191.9 & - & 296.7 & 454.6 \\
\hline MCC-HT2.2\% & & 82,6 & 224.6 & - & 325.9 & 442.8 \\
\hline
\end{tabular}

$\mathrm{Tz}=$ temperature of endothermic peak, $\mathrm{T} ' z=$ temperature of exothermic peak.

Table 4: Values of total weight loss in \% obtained by the thermogravimetric analysis of the samples HT2, HT3, MCC, MCC-HT2.5\%, MCC-HT3.5\% and MCC-HT2.2\%.

\begin{tabular}{|l|l|l|l|l|l|l|}
\hline Compound & HT3 & HT2 & MCC & $\begin{array}{l}\text { MCC- } \\
\text { HT3.5\% }\end{array}$ & $\begin{array}{l}\text { MCC- } \\
\text { HT2.5\% }\end{array}$ & $\begin{array}{l}\text { MCC- } \\
\text { HT2.2\% }\end{array}$ \\
\hline Weight loss (\%) & 40.8 & 37.5 & 79.0 & 62.1 & 65.6 & 51.5 \\
\hline
\end{tabular}

For all the composites CMC-HT2.2\%, CMC-HT2.5\% and CMC-HT3.5\%, we observed the disappearance of the endothermic peak towards $400^{\circ} \mathrm{C}$ corresponding to the departure of water molecules, by dehydroxylation, and of carbonates of Hydrotalcite, which lets think that these species are more related to the synthesized nanomaterial. The two exothermic peaks obtained on the thermograms of CMC-HT2.2\%, CMC-HT2.5\% and CMC-HT3.5\% (Fig.4b), correspond to the decomposition of cellulose in the composite, as was observed by Islam et al. [12] for the cellulose-Hydroxypatite carbonated nanocomposite. This degradation occurs at lower temperatures than those obtained for cellulose alone.The addition of the clay particles altered the structure of cellulose in agreement with our observations by XRD (disappearance of the amorphous phase) and thus it is possible that this modification of the cellulose structure causes the modification of degradation temperature in the nanocomposite or it is due to the state of dispersion of hydrotalcite particles in the polymer.

In the same way, it is noted that the total weight loss at $600^{\circ} \mathrm{C}$ for each sample CMC-HT2.2\%, CMC-HT2.5\% and CMC$\mathrm{HT} 3.5 \%$, is higher than that of pure Hydrotalcite, which is due to the presence of cellulose, and is also lower than that of cellulose alone, owing to the fact that the vaporizable species would be more related to composite materials (Table 4).

The comparison of the thermograms of MCC-HT2.5\% and MCC-HT2.2\%, shows that the total weight loss increases with the increase of $\%$ of the Hydrotalcite in the composite. It also shows that the sample MCC-HT2.2\% has the temperatures T3 and T'1, corresponding respectively to the elimination of water molecules existing in the interlayer space of the Hydrotalcite and at the degradation of cellulose (with the important weight loss), strongest and has the lowest total weight loss (Tables 3 and 4). It results that MCC-HT2.2\% is the nanomaterial most thermically stable. In addition, the analysis by IR spectroscopy revealed a ratio $\mathrm{Iv}_{\mathrm{C}-\mathrm{H}} / \mathrm{Iv}_{\mathrm{O}-\mathrm{H}}$ higher for $\mathrm{MCC}-\mathrm{HT} 2.2 \%$. These results confirm that $2 \%$ of load of Hydrotalcite with ratio $\mathrm{Mg} / \mathrm{Al}=2$ provides a nancomposite with the modified thermic properties compared to $\mathrm{MCC}-\mathrm{HT} 2.5 \%$ and $\mathrm{MCC}$ HT3.5\%.

The thermogravimetric analysis of the samples MCC-HT3.5\% and MCC-HT2.5\%, which shows the same rate of reinforcement and a ratio $\mathrm{Mg} / \mathrm{Al}$ different, indicates that their losses of weight are practically identical, whereas the temperatures of decomposition T3 and T'1 of MCC-HT2.5\% are lower than those of MCC-HT3.5\%. This may be due to the presence of additional phases observed in the XRD analysis for the MCC-HT2.5\% and which lower the nanocomposite stability.

\subsection{TEM analysis}

The morphology of MCC, HT, MCC-HT2.2\% and MCC-HT3.5\% was investigated by TEM. The result is given in Fig.5. It was observed that the samples composites consisted of platelet-like sheets. It can be seen that Hydrotalcite nanoparticles are well dispersed in MCC matrix, and the size of the majority of clay particles is smaller than $100 \mathrm{~nm}$. In addition, in the case of MCC-HT2.2\%, the particles are homogeneously dispersed and have a size of approximately $40-60 \mathrm{~nm}$ (Fig.5c). 


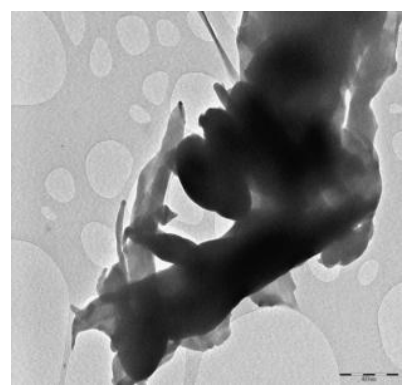

(a) MCC

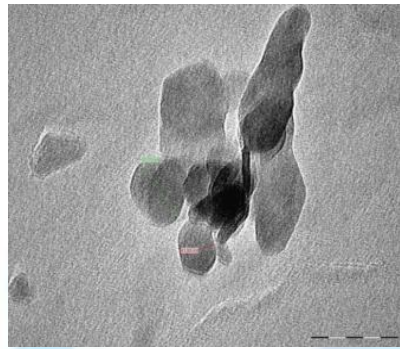

(c) MCC-HT2.2\%

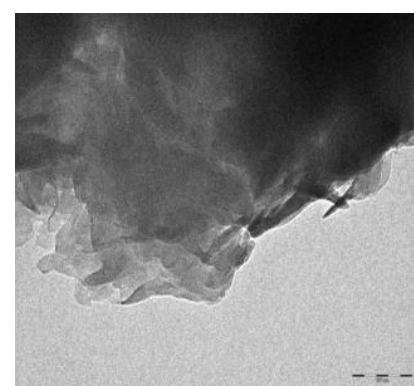

(b) HT3

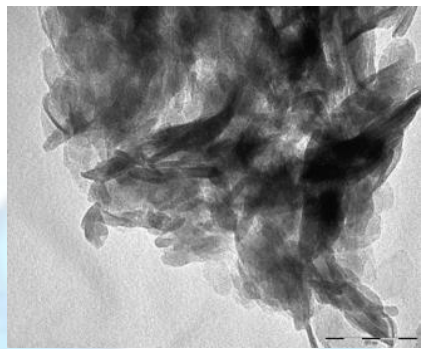

(d) MCC-HT3.5\%

Fig.5: TEM micrographs of a) MCC, b) HT3, c) MCC-HT2.2\% and d) MCC-HT3.5\% naocomposites.

\section{CONCLUSION}

The results obtained in this work show:

- The extracted cellulose microfibers have a high percentage of cellulose and have a good crystallinity;

- The prepared hydrotalcites are in a pure form and a well crystallized phase;

- $\quad$ The nanomaterial developed are composed of two phases, the hydrotalcite phase and the cellulose phase in its crystalline form;

- $\quad$ The TEM analysis shows a good dispersion of clay particle (HT) in polymer matrix (MCC);

- $\quad$ The influences of the rate of reinforcement show that the optima are $2 \%$ for the Hydrotalcite of ratio $\mathrm{Mg} / \mathrm{Al}=2 \mathrm{and}$ $5 \%$ for Hydrotalcite of ratio $\mathrm{Mg} / \mathrm{Al}=3$;

- The Hydrotalcite $\mathrm{MgAlCO}_{3}$ of ratio $\mathrm{Mg} / \mathrm{Al}=2$ gives (comparison between $\mathrm{MCC}-\mathrm{HT} 2.5 \%$ and $\mathrm{MCC}-\mathrm{HT} 3.5 \%$ ) a thermally stable nanomaterial.

Based on the results obtained, the future work will concern the use of cellulose extracted like polymeric matrix and the argillaceous loads the Layered Double Hydroxides "LDHs" for the development of the bionanomaterials.

\section{REFERENCES}

[1] Yano, K., Usuki, A., Kurauchi, T., Kamigaito, O. "Synthesis and properties of polyimide-clay hybrid", 1993, J. Polymer Sci Part A Polym. Chem., 31, 2493-2498.

[2] Yano, K., Usuki, A., Kurauchi, T., Kamigaito, O. "Synthesis and properties of polyimide-clay hybrid films", 1997, J. Polymer Sci Part A Polym. Chem., 35, 2289-2294.

[3] Lee, D. C., Jang, L. W." Preparation and characterization of PMMA-clay hybrid composite by emulsion polymerization",1996, J. App. Polym. Sci., 61, 1117-1122.

[4] Okamoto, M., Morita, S., Taguchi, H., Kim, Y. H. , Kotoka, T., Tateyama, H. "Synthesis and Structure of smectic claypoly(methyl methacrylate) and clay-polysterene nanocomposites via in situ intercalative polymerization", 2000, Polymer, 41, 3887-3890.

[5] Fu, X., Qutubuddin, S. "Synthesis of polystyrene-clay nanocomposites", 2000, Mater Lett., 42, 12-15.

[6] Takagi, H., Asano, A. "Effects of processing conditions on flexural properties of cellulose nanofiber reinforced "green" composites", 2008, Composites Part A : Applied Science and Manufacturing, 39, 685-689.

[7] Matsumura, H., Glasser, W. "Cellulosic nanocomposites, Studies by atomic force microscopy", J. Appl. Polym., 78, 2254-2261. 
[8] Wang, Y., Hsieh, Y. L. "Cellulose functionalization by glutaraldehyde", 2001, Polym Preprints, 42 , 520-521.

[9] Favier, V., Chanzy, H., Cavaille, J. Y. "Polymer nanocomposites reinforced by cellulose whiskers",1995, Macromolecules, 28, 6365-6367.

[10] Hajji, P., Cavaille, JY., Favier, V., Gauthier, C., Vigier, G. "Tansile behavior of nanocomposites from latex and cellulose wiskers", 1996, Polym. Compos., 17, 612-619.

[11] Delhom, C. D., White Ghoorahoo, L.A., Pang, S.S. "Development and characterization of cellulose-clay nanocomposites", 2010, Composites, 41, 475-481.

[12] Islam, M., Chandra Mishra, P., Patel., R. "Arsenate removal from aqueous solution by cellulose-carbonated hydroxyapatite nanocomposites", 2011, J. of Hazardous Materials, 189, 755-765.

[13] Schurz, J."Trends in Polymer Science", A bright futur for cellulose, 1999, Progress in Polymer Science, 24, $481-483$.

[14] Montane, D., Farriol, X., Salvado, J., Jollez, P., Chornet, E. "Application of steam explosion to the fractionation and rapid vapor-phase alkaline pulping of wheat straw", 1998, Biomass Bioenergy, 14, 261-276.

[15] Jia, N., Li, S. M., Zhu, J. F., Ma, M. G., Xu, F., Wang, B., Sun, R.C. "Microwave assisted synthesis and characterization of cellulose-carbonated hydroxypatite nanocomposites in NaOH-urea aqueous solution", 2010, Materials Letters, 64, 2223-2225.

[16] Bendahou, A., Kaddami, H., Raihane, M., Habibi, Y., Dufresne, A. "Nanocomposite material based on date palm tree cellulose whiskers", 2009, Rev. Roum. Chim., 54, 571-575.

[17] Maheswari, U., Obi Reddy, K., Muzenda, E., Guduri, B.R., Varada Rajulu, A. "Extraction and characterization of cellulose microfibrils from agriculural residue-Cocos nucifera L.", 2012, Biomass And bioenergy, 46, 555-563.

[18] Cavani, F., Trifiro, F., Vaccari, A. "Hydrotalcite-type anionic clays: preparation, properties and applications", 1991, Catalysis Today, 11, 173-301.

[19] Reddy, K.O., Guduri, B.R., Rajulu, A.V., "Structural characterization and tensile properties of borassus fruit fibers", J. 2009, Appl. Polym Sci, 114, 603-611.

[20] Sun, XF., Xu, F., Sun, RC., Fowler, P., Baird, MS. "Characteristics of degraded cellulose obtained from steamexploded wheat straw". 2005, Carbohydr. Res., 340, 97-106.

[21] Alemdar, A., Sain M., "Isolation and characterization of nanofibers from agricultural residues-wheat straw and soy hulls". 2008, Bioresour Technol, 99, 1664-1671.

[22] Sain, M., Panthapulakkal, S. "Bioprocess preparation of wheat straw fibers and their characterization", 2006, Industrial Crops and Products, 23,1-8.

[23] Alemdar, A. Sain, M. "Isolation and characterization of nanofibers from agricultural residues-wheat straw and soy hulls", 2008, Bioresource Technology, 99, 1664-1671.

[24] Kaushik, A. Singh, M. "Isolation and characterization of cellulose nanofibrils from wheat straw using steam explosion coupled with high shear homogenization", 2001, Carbohydrate Research, 346, 76-85.

[25] He, Q. Huang, Z., Liu, Y., Chen, W., Xu, T. "Template-directed one-step synthesis of flowerlike porous carbonated hydroxyapatite spheres", 2007, Materials Letters, 61, 41-143.

[26] Ul-Islama, M., Khanab,T., Kon Parka, J. "Nanoreinforced bacterial cellulose-montmorillonite composites for biomedical applications", 2012, Carbohydrate Polymers 89, 1189-1197.

[27] Yong-zhong, Bao, Zhi-ming, Huang, Shen-xing, Li, Zhi-xue, Weng,"Thermal stability, smoke emission and mechanical properties of poly(vinylchloride)-hydrotalcite nanocomposites", 2008, Polymer Degradation and Stability 93,448-455.

[28] Zheng, H., Zhou, J., Du, Y., Zhang, L. "Cellulose-chitin films blended in NaOH/urea aqueous solution", 2002, J. Appl. Polym. Sci. 86, 1679-1683. 